\title{
Distribution of transferrin, ferritin, and lactoferrin in human tissues
}

\author{
D. Y. MASON AND C. R. TAYLOR ${ }^{1}$ \\ From the Department of Pathology, Gibson Laboratories, Radcliffe Infirmary, Oxford, UK
}

SUMMARY An immunoperoxidase staining technique was used for detecting three major ironbinding proteins (transferrin, ferritin, and lactoferrin) in routine histological paraffin sections of ? human tissue. Transferrin was found mainly in hepatocytes, a variety of epithelial and myoepithelial $\stackrel{\omega}{\rightarrow}$ cells, renal tubular cells, and histiocytes. Ferritin was most readily found in histiocytes and liver $\frac{+}{\dot{\omega}}$ cells, with weaker reactions seen in epithelial cells. Lactoferrin was found in lactating breast tissue, $\vec{\sigma}$ bronchial glands, polymorphs, and gastric and duodenal epithelial cells. The technique is potentially음 valuable for investigating abnormal iron states.

In recent years a variety of intracellular constituents have been detected in human tissues by immunoperoxidase staining of formalin-fixed, paraffinembedded tissues. Substances detected include immunoglobulin (Taylor and Burns, 1974), gastrin (Piris and Whitehead, 1974) and other hormones (Heyderman and Neville, 1976), lysozyme (Mason and Taylor, 1975), hepatitis B antigen (Burns, 1975), and carcinoembryonic antigen (Goldenberg et al., 1976). These findings considerably extend the potential scope of current histological investigation, since the distribution of these substances in routine surgical tissue specimens from a wide range of disease states may be examined without the need for special fixation and preservation techniques.

We have explored the applicability of the immunoperoxidase technique to demonstrating transferrin, lactoferrin, and ferritin in paraffin sections. Our results show that it is potentially valuable in studying the cellular distribution of these ironbinding proteins in diseases characterised by abnormal iron status.

\section{Material and methods}

Paraffin-embedded blocks of various tissues were obtained from the surgical histological department of the Radcliffe Infirmary. The tissues had been

'Present address: Department of Hematopathology, University of Southern California School of Medicine, Los Angeles, California 90033, USA.

Received for publication 3 October 1977 routinely processed on the laboratory Histokinettes by the recommended schedule, using industrial methylated spirit and chloroform after adequate fixation in neutral formalin.

Rabbit antisera to transferrin and lactoferrin, swine anti-rabbit IgG antiserum, and peroxidase: anti-peroxidase complexes (PAP) were obtained from Dakopatts A/S. Rabbit anti-ferritin antiserum 2 was obtained from Behringwerke AG.

IMMUNOHISTOLOGICAL STAINING An immunoperoxidase technique (the PAP method of Sternberger et al., 1970) was used as previously described (Taylor and Mason, 1974; Mason and? Taylor, 1975). In this procedure (summarised in Table 1) a peroxidase-labelled 'sandwich' of specific'ô antisera is applied to dewaxed paraffin sections. The

Table $1 P A P$ (peroxidase:antiperoxidase) immunohistochemical method*

\begin{tabular}{ll}
\hline Stage No. & Procedure \\
\hline 1 & $5 \mu$ paraftin section-xylol-absolute ethanol \\
2 & Block endogenous peroxidase with methanol $\mathrm{H}_{2} \mathrm{O}_{2}$ \\
3 & Normal swine serum, 30 min \\
4 & Rabbit anti-transferrin, -ferritin or -lactoferrin, 30 min \\
5 & Swine anti-rabbit IgG, 30 min \\
6 & PAP (peroxidase :rabbit antiperoxidase complexes), \\
7 & Do min \\
8 & Ciaminobenzidine $\mathrm{H}_{2} \mathrm{O}_{2}$ reaction, 5-10 min \\
& Counterstain with haematoxylin, dehydrate, mount in \\
\hline
\end{tabular}

*The PAP technique depends on the ability of the antiserum in stage $5 \overparen{D}$ (antirabbit IgG) to act bivalently, binding via one Fab region to the primary rabbit antibody of stage 4 , and by the other Fab portion to $\mathbb{D}$ the rabbit IgG in the PAP immune complexes, thus creating a peroxidase labelled triple 'sandwich' of antibodies. 
Table 2 Tissues giving positive immunoperoxidase reactions with antisera to transferrin, ferritin, and lactoferrin. Parentheses signify weak or inconstant reactions. Positive staining of cells widely distributed in different tissues (for example, lactoferrin in polymorphs) not separately indicated

\begin{tabular}{|c|c|c|c|}
\hline Tissue & Transferrin & Ferritin & Lactoferrin \\
\hline \multicolumn{4}{|l|}{ GI tract } \\
\hline Liver & Hepatocytes (Kupffer cells) & Hepatocytes, Kupffer cells, portal tract histiocytes & Negative \\
\hline Stomach & Parietal cells & Epithelial cells (parietal cells) & Mucus neck cells \\
\hline Duodenum & Epithelial cells & Epithelial cells & Epithelial cells \\
\hline Gall bladder & Epithelial cells & Negative & Negative \\
\hline \multicolumn{4}{|l|}{ Endocrine } \\
\hline Thyroid & Colloid & Negative & Negative \\
\hline \multicolumn{4}{|l|}{ Genitourinary } \\
\hline Kidney & Tubular cells & Proximal tubular cells & Negative \\
\hline Uterus & $\begin{array}{l}\text { Cervical epithelium, } \\
\text { myoepithelial cells }\end{array}$ & Cervical epithelium & (Cervical glandular cells) \\
\hline \multicolumn{4}{|l|}{ Exocrine glands } \\
\hline Mammary tissue & Periductular cells & Periacinar cells & Acinar cells. Milk \\
\hline $\begin{array}{l}\text { Bone marrow } \\
\text { Reticuloendothelial system }\end{array}$ & \multicolumn{2}{|c|}{ Reticuloendothelial system } & Myeloid cells \\
\hline Histiocytes & $\begin{array}{l}\text { Strongest in activated } \\
\text { histiocytes }\end{array}$ & Strong in many histiocytes & Negative \\
\hline \multirow{2}{*}{$\begin{array}{l}\text { Skin } \\
\text { Respiratory system } \\
\text { Bronchi }\end{array}$} & Epidermal cells & (Epidermal cells) & Negative \\
\hline & Negative & Negative & Glandular cells \\
\hline
\end{tabular}

sites of antibody binding are then shown by developing the peroxidase reaction with a diaminobenzidine/ $\mathrm{H}_{2} \mathrm{O}_{2}$ substrate, which produces a permanent brown reaction. After haematoxylin counterstaining sections are mounted in DPX and examined by orthodox light microscopy. Optimal dilutions of antisera were determined in preliminary studies to give maximum sensitivity with a minimum of nonspecific staining.

Controls for the specificity of the immunoperoxidase reactions involved omitting the primary antiserum (whereupon negative reactions were obtained) and also comparing the reactions for the three different proteins investigated (for example, antilactoferrin reacted positively with breast tissue and was negative on liver sections, while anti-transferrin gave the reverse pattern).

\section{Results}

The results of this study are summarised in Table 2 . The reactions of tissues in which positive staining was observed are considered in detail below under the heading of the three proteins studied.

\section{TRANSFERRIN}

In most tissues there was background staining of variable degree intravascularly and in the intercellular spaces. This staining, which is presumably accounted for by the ubiquitous distribution of transferrin in blood and extracellular fluid (Morgan, 1974), was minimised by the use of an appropriate anti-serum dilution, enabling genuine positivity due to intracellular transferrin to be identified.

\section{Liver}

In all samples parenchymal cells reacted positively but the intensity of staining varied considerably, both from cell to cell within a single section and between different specimens (Figs. 1, 2). Positive cells occurred in groups or as isolated units and did not follow a clear anatomical distribution, though there was some tendency towards periportal clustering. Kupffer cells showed moderate staining in some samples but were negative in other specimens.

\section{Stomach}

In all sections examined parietal cells showed granular staining which varied in intensity from case to case. Samples from cases of atrophic gastritis showed, in addition to the parietal cell reaction, striking staining of epithelial cells in areas of intestinal metaplasia.

Five cases of gastric carcinoma were studied and in three intense granular positive staining was seen within recognisable tumour cells, with rather fainter staining in a fourth case. Positive cells were found either in isolation or in small groups, and the reaction was most intense towards the luminal border of the cells.

\section{Duodenum}

Strong granular staining of epithelial cells was noted both at the tips of villi and in cells lying along the sides of the villi. The reaction was most intense just beneath the brush border of the cells.

\section{Gall bladder}

Scattered epithelial cells in this organ were positive (Fig. 3). 


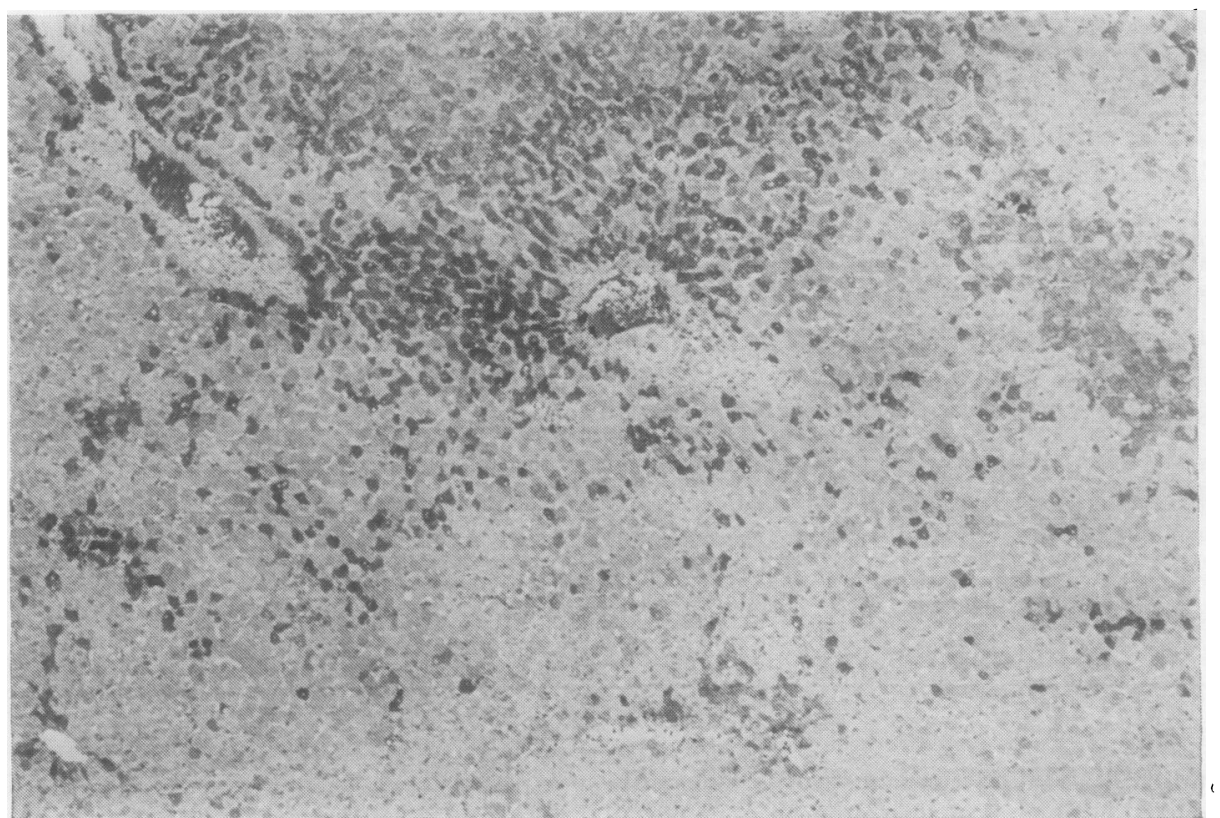

Fig. 1 Hepatic tissue stained for transferrin. Note irregular distribution of positive hepatocytes.

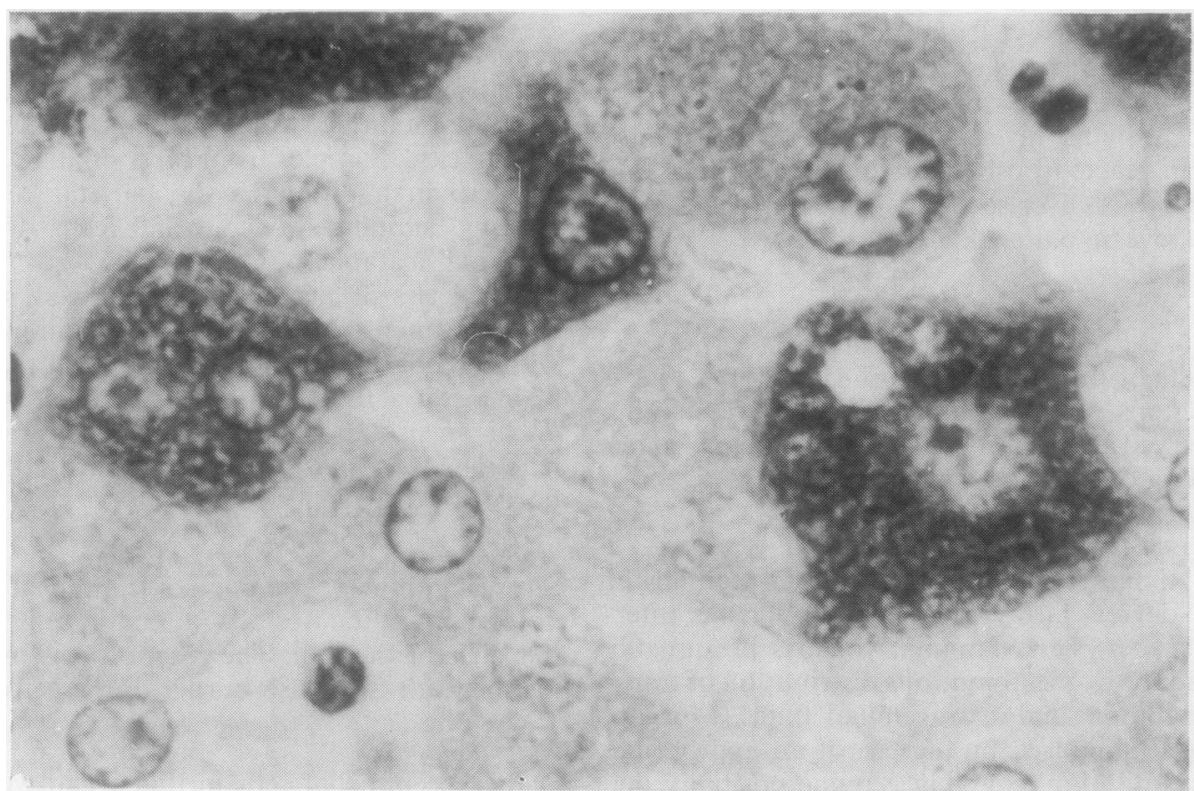

Fig. 2 Higher magnification of transferrin-positive hepatocytes shown in Fig. 1. 


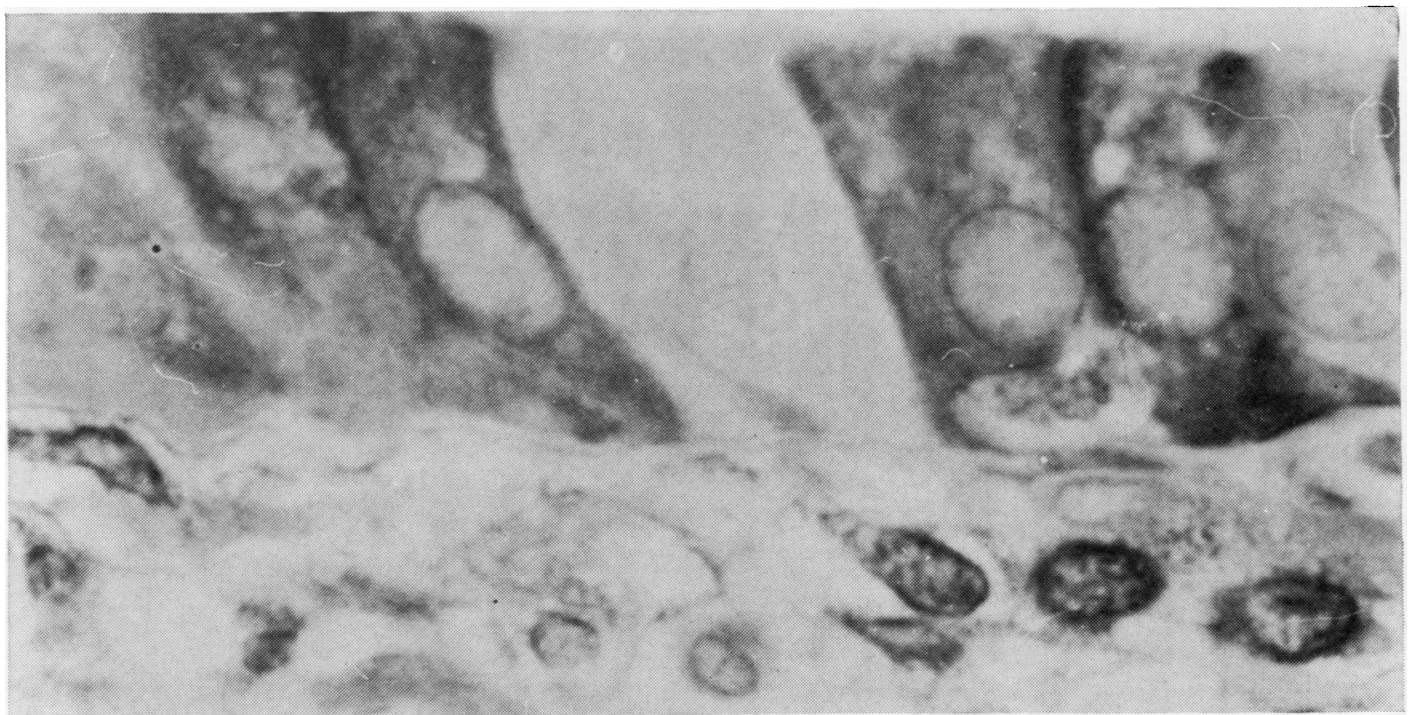

Fig. 3 Transferrin in gall bladder epithelial cells. Note negative cell contrasting with adjacent strongly positive cells.

\section{Thyroid}

Intrafollicular colloid in this organ stained positively but no cellular staining was observed.

\section{Kidney}

Intraluminal material throughout the tubular length stained for transferrin. There was also cytoplasmic staining of a proportion of cells in the loop of Henle, distal tubule, and collecting tubules giving a contrast between adjacent positive and negative cells resembling that seen in gastrointestinal epithelium. Most proximal tubular cells were transferrinpositive, but staining was predominantly at the luminal border of the cells.

\section{Testis}

Interstitial cells stained weakly.

\section{Uterus}

Scattered squamous epithelial cells of the uterine cervix stained strongly. Perivascular myoepithelial cells associated with spiral arteries in the endometrium were also positive (Figs. 4, 5).

\section{Mammary tissue}

Periductular myoepithelial cells were transferrin positive.

\section{Histiocytes}

Histiocytes in dermal histiocytomata and xanthomata stained weakly. In contrast, activated histiocytes in granulomata (Crohn's disease and sar- coidosis) stained much more intensely. The reactions of Kupffer cells are described above.

Skin

A small proportion of epidermal cells stained strongly for transferrin (Fig. 6). Positive cells tended to lie in the stratum lucidum and were more numerous and more intensely staining in samples showing evidence of active chronic dermatitis than in normal skin samples. Positive epidermal cells were also found in sections of squamous cell and basal cell carcinomata (Figs. 7, 8). In the former positivity appeared to be related to the degree of cell maturation and to evidence of keratinisation.

\section{FERRITIN}

In contrast to the ubiquitous background staining encountered when staining tissues for transferrin there was little labelling of this sort with anti-ferritin antiserum, presumably because of its low serum concentration.

\section{Liver}

Hepatocytes showed staining patterns similar to those observed for transferrin (Fig. 1 and 2) with positive cells scattered singly and in sheets through the parenchyma (Figs. 9, 10), although the staining reactions were consistently weaker than those for transferrin. In contrast to the transferrin reaction, Kupffer cells were positive for ferritin, in some cases staining very intensely (Fig. 11). In a few cases portal tract histiocytes were also strongly 


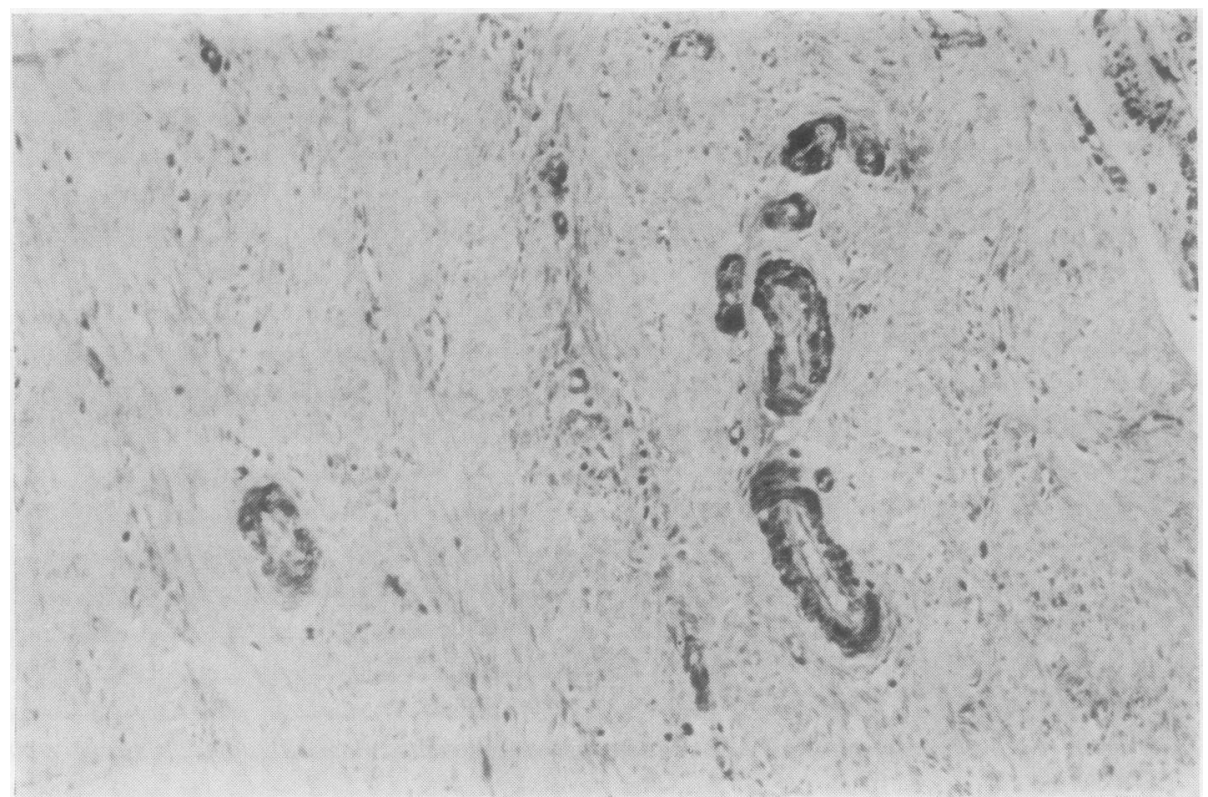

Fig. 4 Transferrin in walls of uterine spiral arteries.

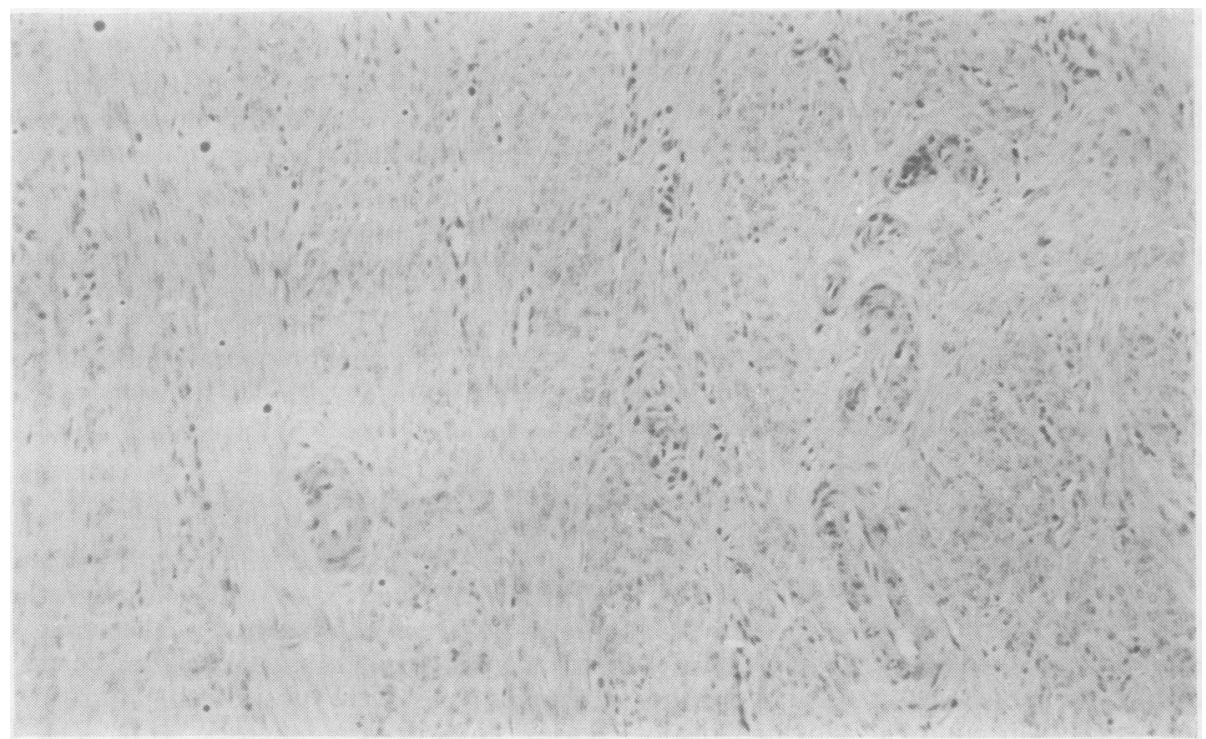

Fig. 5 Negative staining of adjacent section for lactoferrin. 


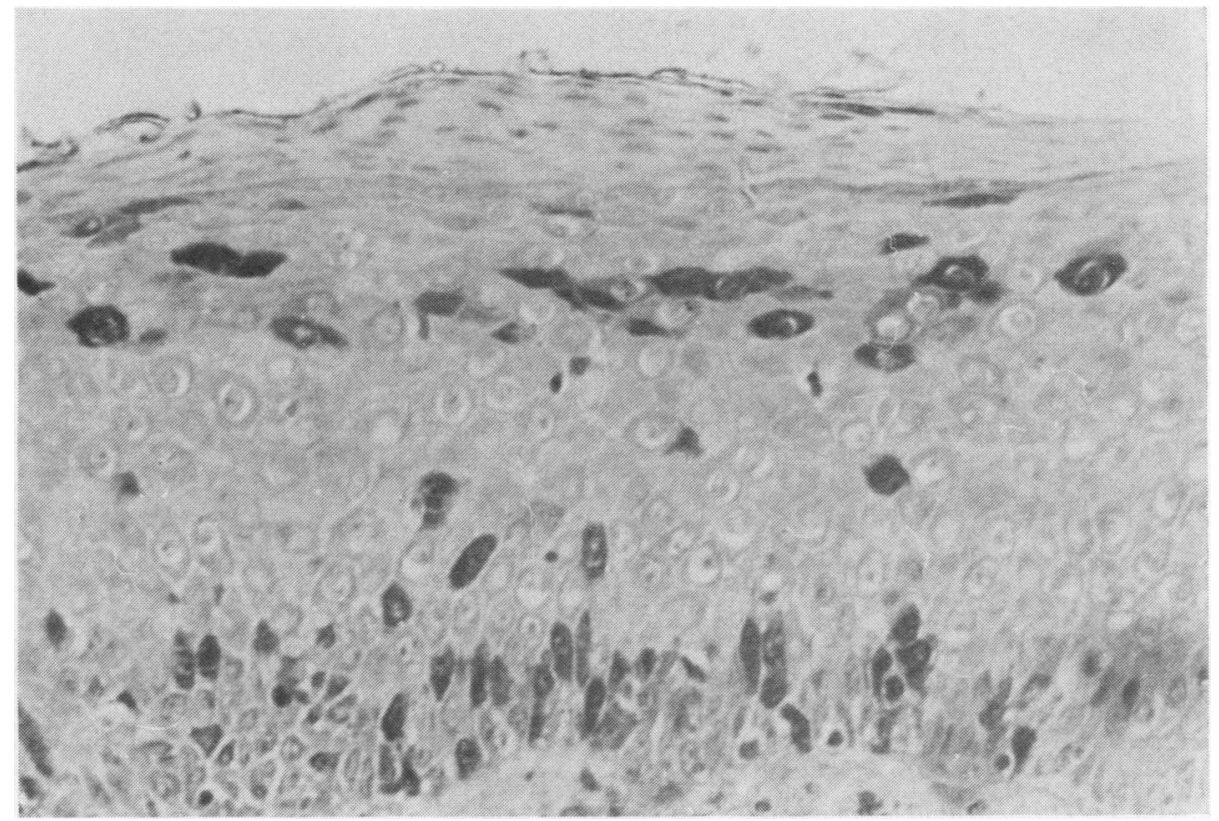

Fig. 6 Transferrin in epidermal cells.

stained (Fig. 12), and in these sections significant amounts of iron could be detected by the Prussian blue reaction. There was no obvious correlation in individual cases between the pattern of parenchymal cell, Kupffer cell, and portal tract histiocyte staining.

\section{Stomach}

A proportion of gastric epithelial cells stained for ferritin in three out of five samples studied. Positive cells were always of the mucous-secreting type typical of gastric mucosa and there was no clear morphological distinction between positive and negative cells. In two out of five cases faint parietal cell staining was observed. Cases of atrophic gastritis showed, in addition to the normal epithelial positivity noted above, staining in areas of intestinal metaplasia which was often intense and sharply demarcated from adjacent normal non-metaplastic gastric epithelium.

\section{Duodenum}

Positive reactions were noted within epithelial cells at the tips of villi, similar in distribution to that of transferrin.

\section{Kidney}

Cytoplasm of proximal cells stained diffusely.

\section{Uterus}

Cervical epithelial cells stained weakly.
Mammary tissues

In one sample, showing pregnancy changes, positive periacinar cell staining was noted.

\section{Bone marrow}

Strong ferritin positivity was seen in marrow histiocytes after multiple transfusions. Histiocyte staining in normal marrow was weaker.

\section{Histiocytes}

Staining of histiocytes in xanthomata and granulomata was very intense. In many tissues scattered positive histiocytes were present, though they stained less intensely.

\section{Skin}

In some samples there was weak staining of squamous epithelial cells. Dermal histiocytes were also positive.

\section{LACTOFERRIN}

Background staining in lactoferrin-stained slides was minimal, in keeping with its low serum concentration. In most tissues positively staining polymorphs were identifiable.

\section{Stomach}

A proportion of mucous neck cells in the body and antral mucosa stained positively and they were 
Fig. 7 Transferrin in a squamous cell carcinoma of skin.

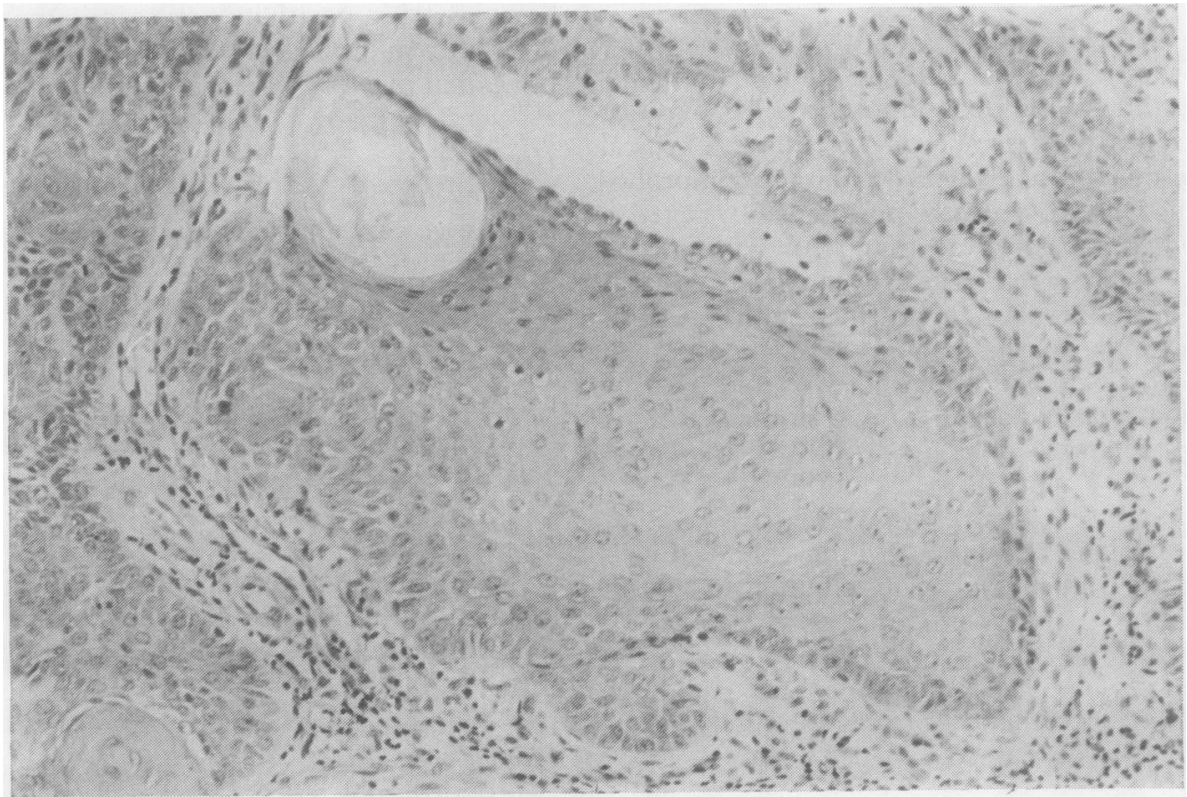

Fig. 8 Negative staining of adjacent section for lactoferrin. 


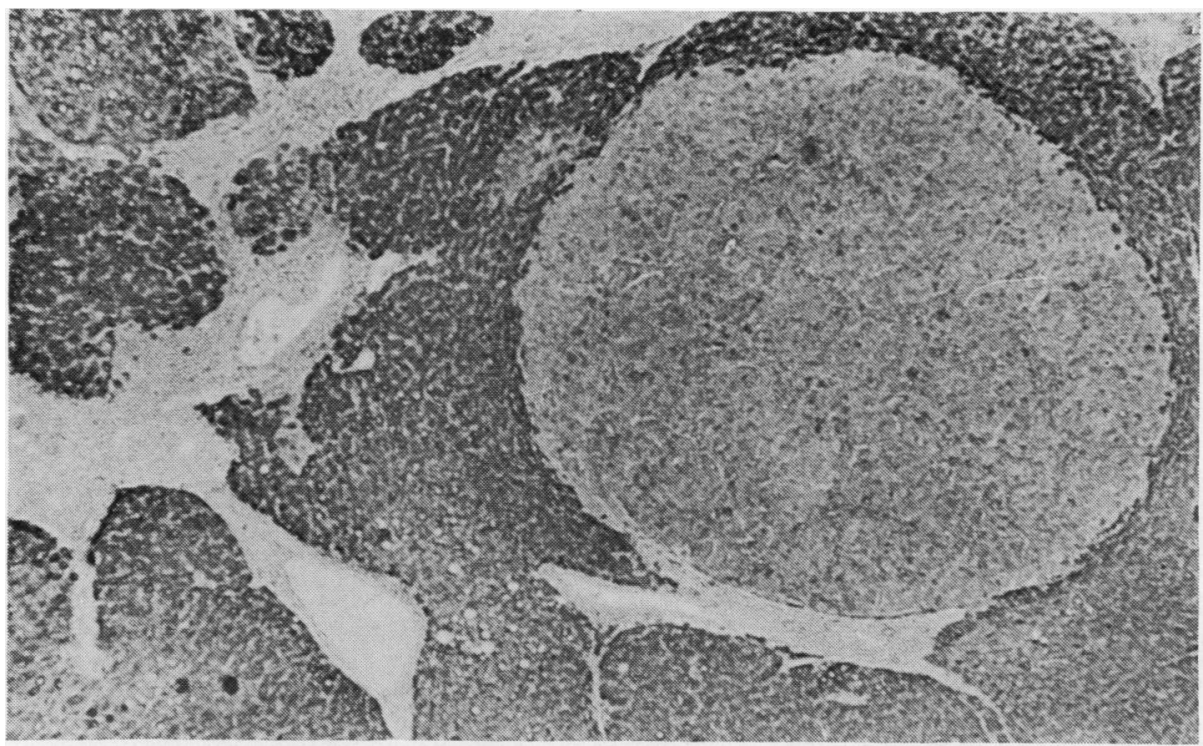

Fig. 9 Ferritin in section of liver tissue. Note predominantly negative regenerating nodule.

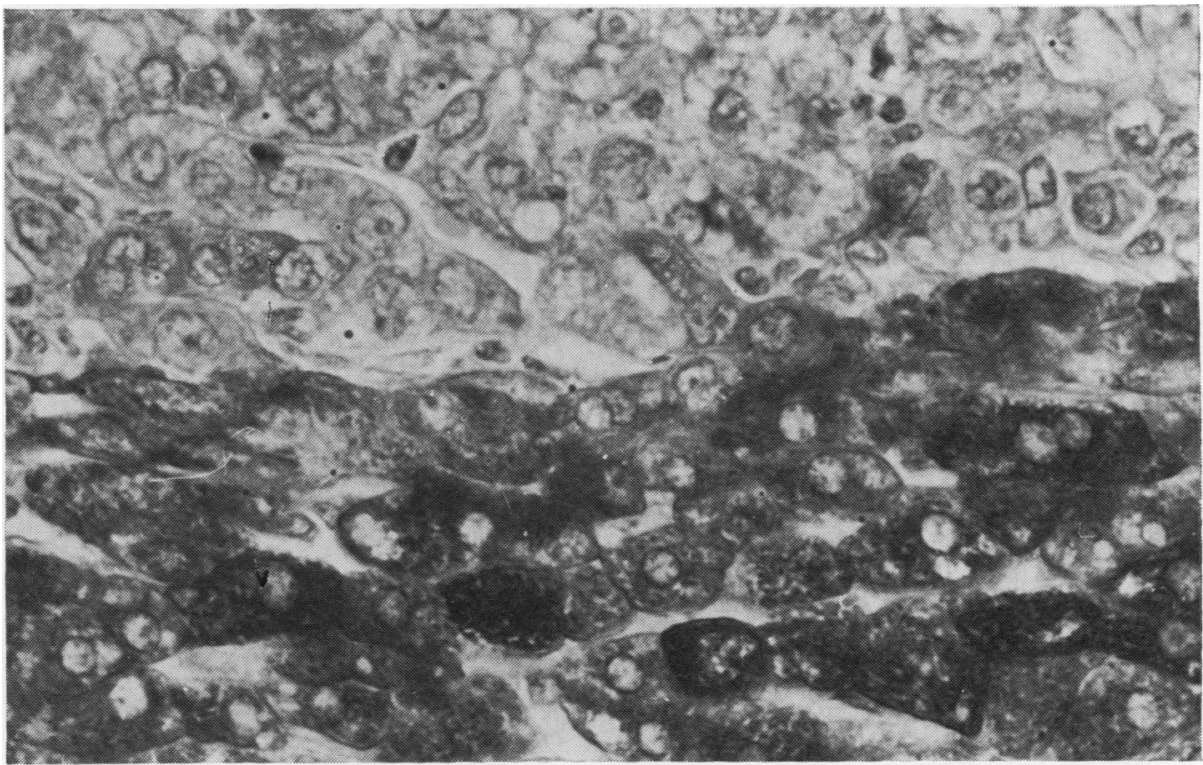

Fig. 10 Higher magnification of edge of nodule in Fig. 9. 


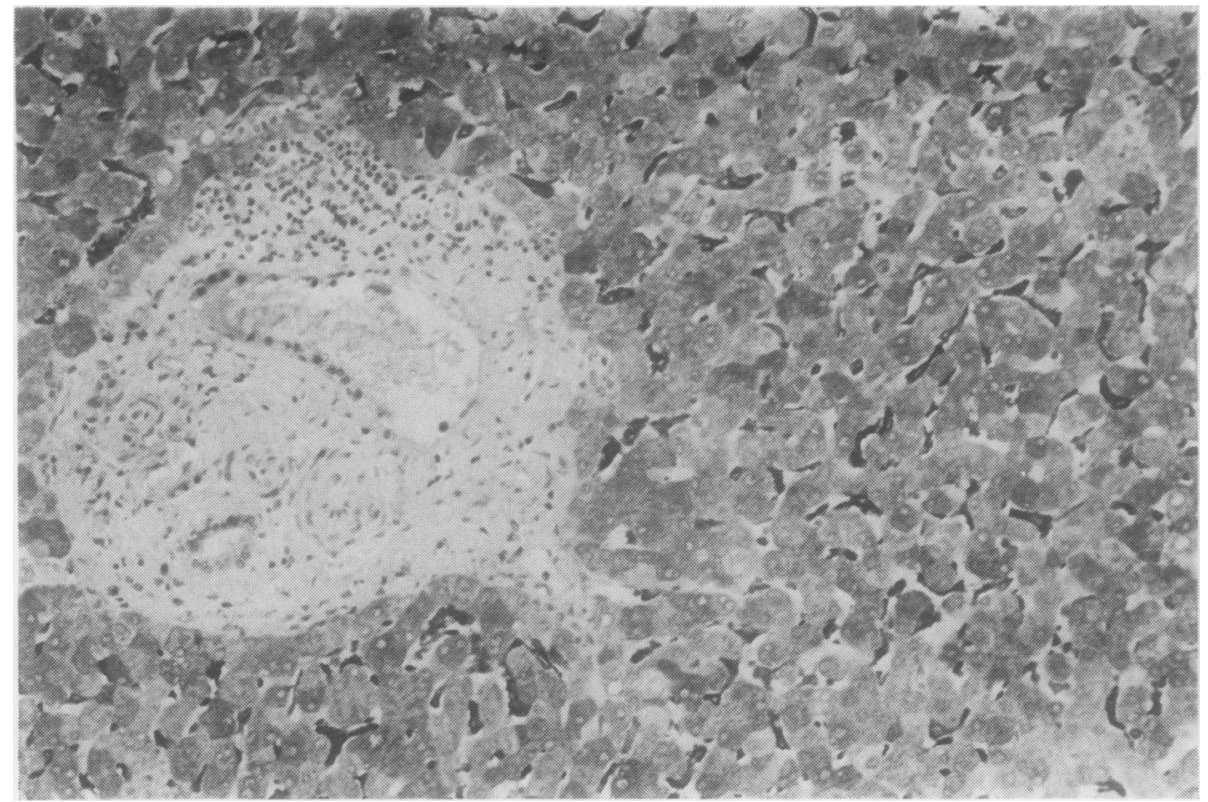

Fig. 11 Kupffer cells and hepatocytes staining for ferritin.

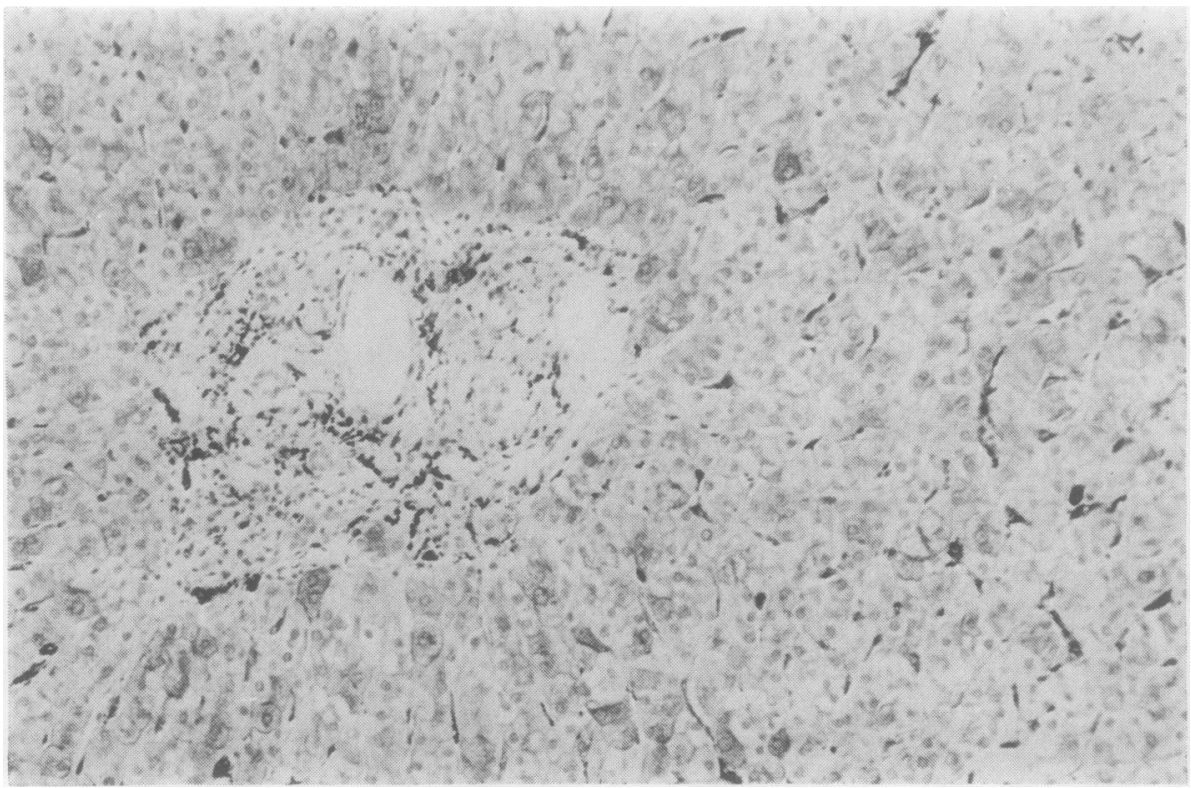

Fig. 12 Kupffer cell and portal tract histiocytic staining for ferritin. 


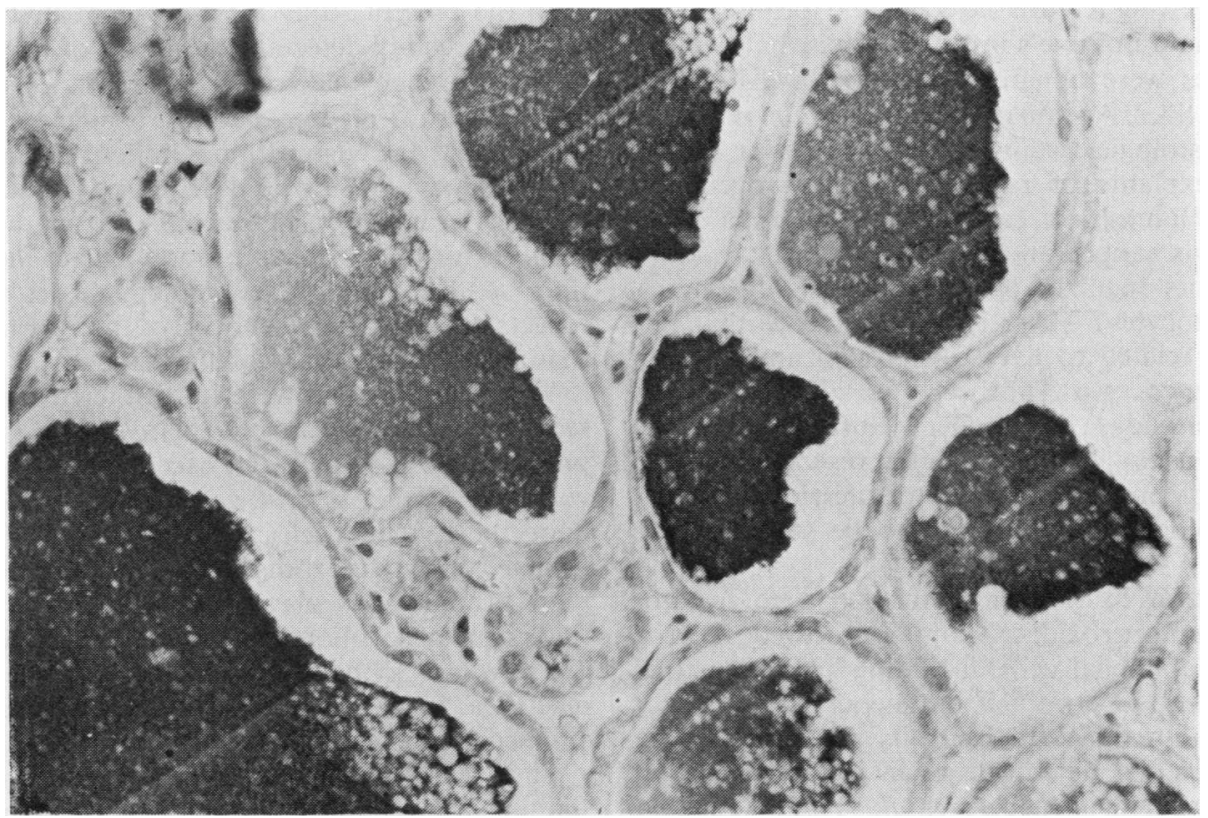

Fig. 13 Lactating breast tissue showing strong staining of secretions for lactoferrin.

clearly demarcated from adjacent negative ones. In areas of intestinal metaplasia positive epithelial cell staining was observed. Gastric carcinoma specimens were negative except in one sample (which was negative for transferrin) in which there were scattered strongly positive cells including some with bizarre nuclear morphology.

\section{Duodenum}

Lactoferrin was detected in some intestinal epithelial cells of the absorptive type. Unlike transferrin (see above), this reactivity was usually confined to the tips of villi. Positive cells tended to be in groups which were clearly demarcated from adjacent negative ones.

\section{Uterus}

In one sample (a cervial biopsy showing mild chronic cervicitis) lactoferrin-positive glandular cells were noted, but other samples showed no staining of this sort.

\section{Mammary glands}

Lactating breast tissue stained strongly for lactoferrin both in glandular cells and in their secretions (Fig. 13). One case of mammary carcinoma, out of twelve studied, showed positive staining of malignant cells for lactoferrin.
Skin

The squamous epithelium in most samples was negative for lactoferrin. One basal cell carcinoma showed a few areas of moderate positivity, particularly in the vicinity of hair follicles, although these structures were clearly negative in normal skin.

\section{Bronchial gland}

This tissue showed positive staining for lactoferrin within glandular cells.

\section{Discussion}

The reactions reported above may be discussed in relation to the three different iron-binding proteins investigated. Each of the three antisera produced a separate distinct pattern of staining in the different tissues examined and positive cells were clearly distinguishable from negative cells, thus providing valuable intrinsic controls for this study. We found no evidence of significant cross reactivity between the three antisera.

\section{TRANSFERRIN}

The immunohistological demonstration of transferrin in the liver is in keeping with biosynthetic data, which show that it is the major site of transferrin production in adult man (Morgan, 1974), and with immunofluorescent studies, which have found transferrin in human hepatocytes (Lane, 1967). 
An interesting feature of its hepatic localisation in our study and in Lane's investigation is that positive hepatocytes were apparently randomly distributed within the liver. A similar pattern has been noted on immunohistological staining of human liver and of cultured explants of rat liver for fibrinogen and albumin (Hamashima et al., 1964; Guillouzo et al., 1976). This appearance prompts the question: what factors regulate protein synthesis in individual hepatocytes? There is some evidence that this activity is related to liver cell growth and division (for references see Thorbecke et al., 1973). The immunoperoxidase technique we used may enable the relationship between cellular regeneration and synthesis of proteins such as transferrin in normal and pathological human liver to be studied more closely.

In addition to localising transferrin to hepatocytes immunoperoxidase staining showed it in a variety of epithelial cells, including gastrointestinal mucosa, and in stratified cutaneous and cervical epithelium. In the former site its presence may be related to its postulated role as an intracellular iron transport protein (Huebers et al., 1975) acting in concert with mucosal ferritin.

However, in non-absorptive epithelial tissues no such role can be envisaged. One possibility is that epithelial transferrin plays a role in non-specific immunity against micro-organisms by chelating free iron. There is some evidence for this in the observation that the growth of a skin inoculum of bacteria is greatly enhanced by the presence of free iron (Miles et al., 1976) and in the report by King et al. (1975) that the growth of common dermatophytic fungi is inhibited by unsaturated transferrin.

Transferrin was also demonstrated by immunoperoxidase staining in myoepithelial cells in a variety of tissues. This previously unreported localisation of the protein is unexplained. If it is related to the need for these cells to absorb iron for myoglobin synthesis the negative reaction of other types of muscle cell requires explanation.

\section{FERRITIN}

Although most of the body's ferritin is in the liver (Prieto et al., 1975) small amounts can be extracted from many other tissues, including the spleen, heart, lung, kidney, pancreas, thyroid, brain, adrenal, intestine, placenta, and bone marrow (Harrison et al., 1974; Crichton, 1975). It is not clear, however, from previous work to what extent ferritin in these tissues is parenchymal (where it may represent the individual cells' iron store) or within histiocytic cells (where it may be considered part of the organism's general reticuloendothelial iron store).
In the present study it was evident that the liver contains readily detectable amounts of ferritin both $\overrightarrow{0}$ within parenchymal cells, where its distribution followed an irregular pattern similar to that of $\overrightarrow{\vec{m}}$ transferrin, and also within Kupffer cells and portal $\frac{\sigma}{0}$ tract histiocytes. Ferritin differs fundamentally from transferrin, however, in that it is not synthesised by $\frac{\bar{\omega}}{\omega}$ the liver for release in large amounts into the circula- $\bar{\Phi}$ tion, so that its presence in hepatocytes probably reflects a role in the turnover of body iron rather $\omega$ than synthesis for extracellular export.

When other tissues were studied ferritin was often seen in histiocytic cells but relatively rarely in non- $\mathscr{\sigma}$ phagocytic cells. The major exception to this pattern was in the gut where it was found in gastric and duodenal epithelial cells, the latter distribution being similar to that of transferrin. The fact that both these proteins may play an important role in intes- $\vec{\sigma}$ tinal iron absorption has been referred to above. There was a further similarity between the staining reactions for the two proteins in cervical and cutaneous epithelial cells.

The variability of the intensity of histiocytic staining for ferritin in samples of the same tissue from different individuals was striking (compare with the results of liver staining) and may be related to the iron status of the individuals from whom the samples were taken. Future studies to explore the relationship between the staining reactions for these two binding proteins and parameters such as serum $\stackrel{\mathbb{D}}{\mathbb{2}}$ iron and ferritin levels and stainable tissue iron are $\overrightarrow{\vec{\rho}}$ indicated. A preliminary observation of this sort has been made by Bieber and Bieber (1973), who showed that raised serum levels of ferritin in cases $\overline{0}$ of Hodgkin's disease are mirrored by the immunfluorescently demonstrable presence of this protein ? within splenic cells.

\section{LACTOFERRIN}

The observations reported above are largely in agreement with the work of Masson and his colleagues, 은 who provided immunohistological evidence for the $D$ presence of this protein in human breast, bronchial glands (Masson and Heremans, 1966), and in neutro- N phil polymorph cytoplasm (Masson et al., 1969).

The demonstration of lactoferrin in cells from the $\tilde{N}$ upper gastrointestinal tract (gastric mucous neck $\omega$ cells, duodenal epithelial cells) has not been previously reported. Possibly this finding is related to 0 mucosal defence mechanisms-by analogy with the presence of lysozyme in gastric glandular cells $\stackrel{\odot}{\rightarrow}$ (Klockars and Reitamo, 1975, and personal un- $T$ published observations). Possibly also the protein has some role in mucosal iron transport-by $\Omega$ analogy with the similar appearance of transferrin $\mathbb{D}$ staining in intestinal epithelial cells. 


\section{Conclusion}

This study shows that the three major iron-binding proteins in man can be detected by immunoperoxidase staining of paraffin-embedded tissues, a finding which considerably extends the potential range of normal and pathological human tissues that can be retrospectively studied. Their distribution as revealed by this technique broadly followed the patterns established in previous studies. However, in addition these proteins have been demonstrated in tissues where their presence was previously unsuspected. Further studies are indicated to elucidate the significance of these findings in terms of normal metabolism and in relation to disease processes, particularly disorders of iron metabolism.

We thank Dr J. Skinner for advice on gastrointestinal sections, Dr T. Parry for photographic assistance, and Mrs J. Braidwood for typing the manuscript.

\section{References}

Bieber, C. P., and Bieber, M. M. (1973). Detection of ferritin as a circulating tumor-associated antigen in Hodgkin's disease. National Cancer Institute Monographs, 36, 147-157.

Burns, J. (1975). Immunoperoxidase localisation of hepatitis B antigen (HB) in formalin-paraffin processed liver tissue. Histochemical Journal, 44, 133-135.

Crichton, R. R. (1975). Ferritin: structure, function and role in intracellular iron metabolism. In Iron Metabolism and its Disorders, edited by H. Kief, pp. 81-89. Excerpta Medica, Amsterdam.

Goldenberg, D. M., Sharkey, R. M., and Primus, F. J. (1976). Immunocytochemical detection of carcinoembryonic antigen in conventional histopathology sections. American Journal of Pathology, 82, 74a-75a.

Guillouzo, A., Feldman, G., and Boisnard, M. (1976). Preparation of liver explant cultures for the demonstration of intracellular proteins. In Immunoenzymatic Techniques, edited by G. Feldmann, P. Druet, J. Bignon and S. Avrameas, p. 99. North Holland, Amsterdam.

Hamashima, Y., Harter, J. G., and Coons, A. H. (1964). The localisation of albumin and fibrinogen in human liver cells. Journal of Cell Biology, 20, 271-279.

Harrison, P. M., Hoare, R. J., Hoy, T. G., and Macara, I. G. (1974). Ferritin and haemosiderin: structure and function. In Iron in Biochemistry and Medicine, edited by A. Jacobs and M. Worwood, pp. 73-114. Academic Press, London.

Heyderman, E., and Neville, A. M. (1976). A shorter immunoperoxidase technique for the demonstration of carcinoembryonic antigen and other cell products. Journal of Clinical Pathology, 30, 138-140.

Huebers, H., Huebers, E., and Rummel, W. (1975). Mechanism of iron absorption: iron-binding proteins and dependence of iron absorption on an elutable factor. In Iron Metabolism and its Disorders, edited by H. Kief, pp. 13-24. Excerpta Medica, Amsterdam.

King, R. D., Khan, H. A., Foye, J. C., Greenberg, J. H., and Jones, H. E. (1975). Transferrin, iron and dermatophytes. 1 . Serum dermatophyte inhibitory component definitively identified as unsaturated transferrin. Journal of Laboratory and Clinical Medicine, 86, 204212.

Klockars, M., and Reitamo, S. (1975). Tissue distribution of lysozyme in man. Journal of Histochemistry and Cytochemistry, 23, 932-940.

Lane, R. S. (1967). Localization of transferrin in human and rat liver by fluorescent antibody technique. Nature, 215, 161-162.

Mason, D. Y., and Taylor, C. R. (1975). The distribution of muramidase (lysozyme) in human tissues. Journal of Clinical Pathology, 28, 124-132.

Masson, P. L., and Heremans, J. F. (1966). Studies on lactoferrin, the iron binding protein of secretions. Protides of Biological Fluids, 14, 115-124.

Masson, P. L., Heremans, J. F., and Schonne, E. (1969). Lactoferrin, an iron-binding protein in neutrophilic leukocytes. Journal of Experimental Medicine, 130, 643-658.

Miles, A. A., Pillow, J., and Khimji, P. L. (1976). The action of iron on local klebsiella infection of the skin of the guinea-pig and its relation to the decisive period in primary infective lesions. British Journal of Experimental Pathology, 57, 217-242.

Morgan, E. H. (1974). Transferrin and transferrin iron. In Iron in Biochemistry and Medicine, edited by $\mathrm{A}$. Jacobs and M. Worwood, pp. 29-71. Academic Press, London.

Piris, J., and Whitehead, R. (1974). An immunoperoxidase technique for the identification of gastrinproducing cells. Journal of Clinical Pathology, 27, 798799.

Prieto, J., Barry, M., and Sherlock, S. (1975). Serum ferritin in patients with iron overload and with acute and chronic liver diseases. Gastroenterology, 68, 525533.

Sternberger, L. A., Hardy, P. H. Jr., Cuculis, J. J., and Meyer, H. G. (1970). The unlabeled antibody enzyme method of immunohistochemistry. Journal of Histochemistry and Cytochemistry, 18, 315-333.

Taylor, C. R., and Burns, J. (1974). The demonstration of plasma cells and other immunoglobulin-containing cells in formalin-fixed, paraffin embedded tissues using peroxidase labelled antibody. Journal of Clinical Pathology, 27, 14-20.

Taylor, C. R., and Mason, D. Y. (1974). The immunohistological detection of intracellular immunoglobulin in formalin-paraffin sections from multiple myeloma and related conditions using the immunoperoxidase technique. Clinical and Experimental Immunology, 18, 417-429.

Thorbecke, G. J., Liem, H. H., Knight, S., Cox, K., and Muller-Eberhard, U. (1973). Sites of formation of the serum proteins transferrin and hemopexin. Journal of Clinical Investigation, 52, 725-731. 